\title{
POSSIBILIDADES DE DIÁLOGOS ENTRE GÊNERO, SEXUALIDADE E RELAÇÕES ÉTNICO-RACIAIS NO ESTÁGIO DE CIÊNCIAS DO ENSINO FUNDAMENTAL EM UMA ESCOLA QUILOMBOLA*
}

\author{
Thaís Santos Santana ${ }^{1}$ \\ Marcos Lopes de Souza ${ }^{2}$ \\ Fernanda Xavier Silva Santana ${ }^{3}$
}

\section{Introdução}

Neste capítulo trabalharemos alguns momentos ocorridos durante o estágio realizado na disciplina Metodologia e Prática do Ensino de Ciências no curso de Licenciatura em Ciências Biológicas da Universidade Estadual do Sudoeste da Bahia, campus de Jequié-BA. Neste estágio foi construída uma proposta de ensino com as temáticas gênero, sexualidade e relações étnico-raciais.

Nesta vivência passamos por algumas situações que nos abalaram, nos perturbaram e nos inquietaram. Tivemos cenas que nos fizeram refletir sobre a posição em que ocupamos quando discutimos gênero, sexualidade e as relações étnico-raciais na escola e os enfrentamentos encontrados quando assumimos esses debates.

Respaldamo-nos em Jorge Larrosa (2002) para pensar a experiência como aquilo "[...] que nos passa, o que nos acontece, o que nos toca. Não o que se passa, não o que acontece, ou o que toca. A cada dia se passam mui-

\footnotetext{
*DOI - 10.29388/978-65-86678-66-6-f.157-174

${ }^{1}$ Licenciada em Ciências Biológicas pela Universidade Estadual do Sudoeste da Bahia (UESB) e Mestranda do Programa de Pós-Graduação em Educação Científica e formação de Professores da UESB, campus de Jequié-BA. Email: taisantana13@hotmail.com.

${ }^{2}$ Licenciado em Ciências Biológicas pela Universidade de São Paulo (USP). Mestre e Doutor em Educação pela Universidade Federal de São Carlos (UFSCar). Professor Titular da Universidade Estadual do Sudoeste da Bahia (UESB), campus de Jequié-BA. Email: markuslopessouza@gmail.com.

${ }^{3}$ Licenciada em Ciências da Natureza pela Universidade Federal do Vale do São Francisco (UNIVASF). Mestra em Educação Científica e Formação de Professores pela Universidade Estadual do Sudoeste da Bahia (UESB), campus de Jequié-BA. E-mail: ssxf.1@hotmail.com.
} 
tas coisas, porém, ao mesmo tempo, quase nada nos acontece" (LARROSA, 2002, p. 21). Experiência não é informação, já que podemos estar informados e nada nos acontecer. A experiência requer:

[...] parar para pensar, parar para olhar, parar para escutar, pensar mais devagar, olhar mais devagar, e escutar mais devagar; parar para sentir, sentir mais devagar, demorar-se nos detalhes, suspender a opinião, suspender o juízo, suspender a vontade, suspender o automatismo da ação, cultivar a atenção e a delicadeza, abrir os olhos e os ouvidos, falar sobre o que nos acontece, aprender a lentidão, escutar aos outros, cultivar a arte do encontro, calar muito, ter paciência e dar-se tempo e espaço (LARROSA, 2002, p. 24).

Desta forma, aqui relataremos questões que nos desestabilizaram e contribuíram, significativamente, para a nossa vontade de continuar resistindo, pois discutir essas questões no espaço escolar, especialmente nos dias de hoje, é um ato de resistência. Resistir ao momento político, resistir às violências contra as mulheres, a população de lésbicas, gays, bissexuais, travestis, transgêneros e intersexuais (LGBTTI+) e a comunidade negra. É enfrentar os retrocessos em relação às políticas públicas educacionais que retiraram os termos gênero, sexualidade e orientação sexual dos seus documentos e contestar os contramovimentos de grupos fundamentalistas e neoconservadores que querem nos amordaçar.

Ao longo de décadas, a resistência esteve presente com as(os) pesquisadoras/pesquisadores e professoras/professores que se propuseram a discutir gênero, sexualidade, as questões étnico-raciais e outras temáticas que lhes atravessam. Se formos analisar o histórico da inserção da educação sexual nas escolas podemos notar como foi árduo e vagaroso esse processo. Infelizmente, ainda nos dias atuais os avanços não são tão significativos como os esperados pelas(os) pesquisadoras/pesquisadores educacionais. A construção desses debates nas escolas ainda está ocorrendo lentamente ou da forma que muitas(os) de nós ainda não consideramos como transgressora (ROSEMBERG, 1985; LOURO, 2001).

Em se tratando do campo do ensino de Ciências e Biologia, há alguns anos autoras(es) têm questionado os discursos produzidos sobre corpo, gênero e sexualidade e as questões étnico-raciais nas aulas de Ciências no ensino fundamental. O corpo ensinado nas aulas de Ciências se constituiu como universal, padronizado, dissecado em partes para ser estudado 
em pedaços e retirado das condições socioculturais em que é produzido, em uma tentativa de separar biologia e cultura, como se este corpo fosse a natureza em si e não uma leitura científica dele. Dessa forma, o corpo vivido é desprezado por este discurso hegemônico (SANTOS, 1997; SILVA, 2008).

Na maioria das vezes, as(s) professoras(es) de Ciências insistem em ensinar o corpo representado pelo homem cisgênero, branco, jovem, magro e sem deficiência, como a referência, e não como uma possibilidade de corpo, uma vez que, existem tantas outras possíveis. Desta forma, as crianças e jovens que se produzem em outros corpos como mulheres, negras/os, indígenas, travestis, transgêneros, intersex, gordas(os), pessoas com deficiência e entre outras(os) são lidas(os) como anormais, feios, excêntricos, desprezados(as) e passíveis de inúmeros processos discriminatórios.

Em relação às questões de gênero, as aulas de Ciências ainda reiteram o discurso de oposição binária entre homem e mulher, privilegiando o primeiro e reiterando o masculino como o dominador em relação à mulher vista como dominada, reforçando assim um processo de hierarquização. Além do que, quando as mulheres são apresentadas nas aulas de Ciências, privilegia-se as cisgêneras brancas, enquanto as negras, indígenas, asiáticas e as de outros grupos étnico-raciais são desprivilegiadas, além da invisibilização das travestis e mulheres trans.

Moro (2001) nos traz que as(os) docentes de Ciências não se atentam a importância de incorporar as contribuições das mulheres à ciência durante suas aulas e não notam os estereótipos de gênero expressos em muitas das ilustrações dos livros didáticos de Ciências dos anos finais do ensino fundamental. Santos (1997) nos relata o quanto os óvulos e espermatozoides são compreendidos em relação à feminilidade e masculinidade, desta maneira, enquanto o óvulo é caracterizado como passivo, imóvel e passível de ser penetrado, o espermatozoide é nomeado como ágil, ativo e penetrador.

Sobre as sexualidades, nas aulas de Ciências, o discurso heterorreprodutivo ainda é potente e (re)produz o pensamento de que as relações afetivas e sexuais estão compulsoriamente atreladas à heterossexualidade e à reprodução visando a produção de novos(as) descendentes. Inclusive os Sistemas Genitais já foram nomeados de Sistemas Reprodutores ou Sistemas Sexuais, construindo sentidos que associavam os órgãos desses sistemas apenas à reprodução e ao sexo, desconsiderando inclusive outras práticas sexuais. A própria associação da vagina como genitália da mulher, ao in- 
vés da vulva, e do pênis como do homem reforça o entendimento do sexo vaginal como prática sexual naturalizada em detrimento de outras e, mais uma vez, o modelo heterorreprodutor é centralizador (FURLANI, 2003).

Ao analisarem os livros didáticos de Ciências dos anos finais do ensino fundamental, Souza e Santos (2013) identificaram a predominância de imagens de homens em relação à de mulheres, uma reiteração de alguns estereótipos de gênero, apesar da existência de outros arranjos nas construções das feminilidades e masculinidades que mostram alguns movimentos de ruptura. Nas coleções analisadas, a heterossexualidade é enfatizada como a expressão natural e legítima da sexualidade enquanto as outras sexualidades são silenciadas.

Diante de como as questões de gênero, sexualidade e étnico-raciais (não) têm sido trabalhadas no ensino de Ciências, nos enveredamos em desenvolver e discutir uma proposta de ensino de Ciências que abordasse as temáticas gênero, sexualidade e etnia/raça em uma escola estadual quilombola do município de Jequié-BA. Neste artigo problematizaremos algumas das vivências construídas durante esta ação educativa.

\section{Percurso metodológico}

Este trabalho foi desenvolvido a partir da atividade de estágio na disciplina Metodologia e Prática do Ensino de Ciências do curso de Licenciatura em Ciências Biológicas da Universidade Estadual do Sudoeste da Bahia (UESB), campus de Jequié-BA. Nesta disciplina foi solicitado que os(as) licenciandos(as) realizassem o estágio em ensino de Ciências para os anos finais do ensino fundamental, no formato de minicursos com duração mínima de 20 horas.

Esse estágio foi feito em grupo pela primeira autora do texto e mais duas pessoas, colegas do curso, quais sejam, Danielle e Wagner. Este minicurso também foi pensado para construir o trabalho de conclusão de curso (TCC) da primeira autora deste artigo, sendo que o segundo autor é o orientador e a terceira autora, a coorientadora. Dessa forma, a primeira autora também produziu material empírico para elaborar seu TCC.

A escola em que realizamos o estágio foi reconhecida em 2007 como instituição de educação quilombola, de acordo com o Ministério da Educação, sendo uma escola estadual do município de Jequié-BA, que atende ao público dos anos finais do ensino fundamental e Ensino Médio. 
A construção da proposta de educação quilombola e de suas escolas advém da resistência e da luta das comunidades quilombolas que denunciam, há séculos, a invisibilidade da cultura quilombola e afro-brasileira, a discriminação, perseguição e o assassinato da população quilombola. As escolas quilombolas foram pensadas na perspectiva de articular o conhecimento escolar e aqueles construídos pelas comunidades quilombolas e promover o reconhecimento e a positivação das identidades negras e quilombolas (CARRIL, 2017).

A escola quilombola em que desenvolvemos este trabalho está localizada no Barro Preto, um bairro de comunidade reconhecido como quilombo urbano, apesar de alguns/algumas estudantes e outras pessoas da comunidade terem dificuldades em se reconhecer como negros(as) ou quilombolas diante dos estereótipos associados a essas identidades (FERNANDES, 2017).

Para a realização da ação educativa convidamos todas(os) as(os) alunas(os) matriculadas(os) no 9o ano do ensino fundamental, turno matutino, da respectiva escola, já que os encontros ocorreriam no contraturno, pelas tardes. As(Os) discentes foram informadas(os) que estavam participando de forma não obrigatória e que a qualquer momento poderiam desistir de participar do trabalho.

Tivemos 16 estudantes inscritas(os) e todas(os) assinaram o Termo de Assentimento e seus familiares o Termo de Consentimento Livre e Esclarecido autorizando a construção de informações da pesquisa e seu uso em publicações. Foram realizados seis encontros de $3 \mathrm{~h}$ cada, no período de 22 de março a 07 de abril de 2016. Das(os) 16 inscritas(os), 12 ficaram até o final.

As questões trabalhadas durante os encontros foram: 1) produções socioculturais dos corpos; 2) hipersexualização dos corpos negros; 3) construções de gênero na sociedade e as interfaces com as relações étnicoraciais; 4) iniciação sexual, masturbação e prazer; 5) saúde sexual e os direitos das(os) adolescentes e 6) sexismo, racismo e lesbohomobitransfobia (LGBTfobia).

Para desenvolver essas temáticas nos encontros foram utilizadas várias estratégias didáticas como:

1) exibição de vídeos e curtas-metragens (A rainha do carnaval considerada 'negra demais'; Globelezo: E se o carnaval fosse ao contrário?; 
Vestido Novo; Depoimento da mãe de João Ivo (gay assassinado no Rio de Janeiro) e Violência contra a mulher - Programa A Liga);

2) clip musical 'A cena' interpretado por Rashid e 'Boa Nova' por Emicida;

3) roda de conversa sobre "Quando é permitida a exposição do corpo";

4) dinâmicas ('E a canoa virou' - relacionada aos preconceitos em nossa sociedade, especialmente sexismo, racismo e lesbohomobitransfobia - 'Corpo: gosto pessoal ou construção social' - alusivo as construções socioculturais dos corpos - 'Pode ou não pode?' - sobre as (im)possibilidades de prazer nas diversas regiões do corpo em homens e mulheres - 'Concordo ou discordo' - referente aos relatos de jovens sobre suas experiências afetivo-sexuais - 'Práticas sexuais e risco de contágio das IST' - concernente às práticas sexuais que podem aumentar ou diminuir os riscos de contágio das IST e sobre a vulnerabilidade de alguns grupos - e Semáforo das IST: sinal amarelo para os riscos - pertinente à discussão de algumas IST mais comuns);

5) discussão de trechos das redes sociais sobre as agressões verbais sofridas por Maria Júlia Coutinho (Maju), Taís Araújo e Thabata Mendes e

6) leitura de texto (Violência obstétrica e relacionamento abusivo).

Para a produção do material empírico deste trabalho foi construído um diário de campo em que ao longo dos encontros e também nos intervalos das atividades foram sendo relatadas as observações mais provocativas pela primeira autora deste texto. Com base em Jorge Larrosa (2002), a primeira autora relatou aquilo que ela parou para escutar, o que a perturbou, a fez olhar com mais atenção e detalhes durante o minicurso. Este diário foi construído com base nas orientações de Bogdan e Biklen (1994).

Nossas análises foram feitas amparando-nos nos referenciais póscríticos e pós-estruturalistas (LOURO, 2007) e, destarte, problematizamos a linguagem enquanto constituição dos sujeitos, questionamos os saberes construídos enquanto verdades em torno das questões de gênero, sexualidade e etnia/raça, investimos nas interpelações e nos estranhamentos em relação às nossas certezas definitivas e naquilo que investigamos, contestamos as perspectivas binárias e dualistas e reconhecemos a importância de pensar e desenvolver as pesquisas como processos abertos e inacabados. 


\section{Cenas que nos aconteceram e nos tocaram durante a prática educativa}

Nesta seção do texto discorremos e discutimos algumas cenas que nos afetaram e nos desestabilizaram durante o minicurso sobre o ensino de Ciências e as questões de gênero, sexualidade e raça/etnia. As análises foram trazidas por meio de dois eixos. O primeiro deles traz cenas relacionadas aos olhares da comunidade escolar sobre as(os) docentes estagiárias(os) e as suas práticas educativas e o segundo explora situações ocorridas durante o minicurso e que se relacionam com a vulnerabilidade das mulheres, especialmente, as negras e a violência cometida contra elas.

\section{Olhares sobre as(os) professoras(es) e as suas práticas pedagógicas}

Neste eixo de discussão trazemos, de início, duas cenas que ocorreram durante os encontros e que tratam da regulação e do questionamento da sexualidade das professoras que ousam dialogar sobre essas temáticas na escola.

No horário do intervalo, enquanto as(os) alunas(os) merendavam e conversavam ao redor do quiosque, local onde estava ocorrendo o primeiro encontro do minicurso, eu e Danielle conversávamos. Durante a conversa, eu toquei no seu cabelo e o coloquei atrás da oreIha, e logo em seguida peguei em seu colar para melhor ver o pingente. Os dois acontecimentos ocorreram em um curto período de tempo, um após o outro. Isso foi suficiente para algumas/alguns alunas(os) que estavam nos observando esboçassem sons como "Huuumm!" e olhares de dúvidas e questionamentos em relação à nossa sexualidade (Cena 1 - $1^{\circ}$ encontro - 22 de março de 2016).

O final do quinto encontro em que se discutiu sobre Saúde sexual e direitos igualitários à saúde pública para todas(os) coincidiu com o término das aulas da escola. Liberamos as(os) alunas(os) e saímos do colégio junto com elas(es). Wagner estava mais a frente e eu e Danielle ainda estávamos próximas à escola, com outros(as) estudantes que estavam indo para suas casas. Então, um aluno que não participava do minicurso e estava acompanhado de outros meninos gritou: 
"Professora, quando vai ser a aula prática de sexualidade?". Após a pergunta eu lhe respondi: "A aula de práticas sexuais e IST foi hoje". Ele e todos os meninos que o acompanhavam começaram a rir (Cena $2-5^{\circ}$ encontro -06 de abril de 2016).

A primeira cena mostra como as(os) profissionais da educação que discutem sexualidade e gênero têm sua sexualidade colocada em xeque, questionada em vários momentos. Neste caso, a demonstração de afeto entre as estagiárias anunciou uma possível lesbianidade. É provável que essa dúvida e desejo de saber qual era a identidade sexual das estagiárias foi compartilhada por outras(os) pessoas do colégio, pois a autora do artigo percebeu outros olhares desconfiados sobre elas na escola.

Ter a heterossexualidade contestada é um discurso recorrente para aquelas e aqueles que insistem em falar sobre essas temáticas não só na escola como também na universidade, especialmente, se pesquisam sobre diversidade de gênero e sexual. Parece-nos que quem assume esse debate é tido como quem apresenta um gênero e uma sexualidade desviantes e dissidentes e, portanto, quem estaria enquadrada(o) na referência da norma, ou seja, homem branco e heterossexual jamais assumiria este trabalho, na leitura de muitos(as).

Na pesquisa-intervenção desenvolvida por Santos e Souza (2015) em aulas de Ciências para a turma de Educação de Jovens e Adultos, a primeira autora discorre como teve sua sexualidade questionada por um discente em uma das aulas, em que ele lhe perguntou se ela gostava de homem ou de mulher. A pesquisadora-professora ficou embaraçada com o questionamento, pois não esperava que alguém fosse lhe perguntar isso, mas ela respondeu dizendo que era heterossexual. Para o estudante que questionou foi um alívio, pois ele mesmo disse, posteriormente, que se recusaria a assistir as aulas dela, caso fosse lésbica, nos mostrando a presença marcante da lesbohomobitransfobia no espaço escolar também por parte de discentes.

Serem lidas como lésbicas não incomodou as estagiárias, o que nem sempre acontece com as professoras e os professores, inclusive muitas/os não querem realizar esse debate com temor de serem identificadas/os como tais, mesmo que alguns/algumas sejam gays, lésbicas ou bissexuais. Por outro lado, se elas fossem um casal de lésbicas, como analisariam essas suspeitas das(os) discentes? Isso as incomodaria? Poderia fazê-las recuar ao 
debate? E se elas assumissem essa lesbianidade para a turma, como seriam lidas? Questões que permanecem.

Começamos a discussão da segunda cena retomando a pergunta do aluno feita às duas estagiárias: "Professora, quando vai ser a aula prática de sexualidade"? Pela elaboração da frase, pelo tom sarcástico/debochado, pela risada ao ser respondida e também por ser proferida por um estudante que não estava no minicurso, essa cena nos aponta possibilidades de leituras das aulas sobre sexualidade como espaços subversivos na escola, associados ao incentivo ao sexo indiscriminadamente. Ao fazer a pergunta, o discente coloca as professoras em uma saia justa, talvez com o intuito de constrangê-las. Porém, Thaís, a primeira autora do artigo, responde que a aula de práticas sexuais tinha ocorrido naquele dia, provocando alguns risos neles e encerrando a conversa.

Ao mesmo tempo, as docentes que investem em dialogar sobre essas temáticas são construídas como promíscuas e depravadas, com uma sexualidade desregrada, levando muitos(as) discentes, especialmente os garotos, a se sentirem autorizados(as) em assediá-las ou inibí-las perante os(as) outros(as).

Na próxima cena discorremos sobre os interesses que estudantes de outras turmas tinham pelo nosso trabalho com as temáticas sobre gênero, sexualidade e relações étnico-raciais.

O nosso quinto encontro ocorria no refeitório da escola, desta vez falávamos de Saúde para a sexualidade. Dentro da temática discutíamos práticas sexuais, o contágio de Infecções Sexualmente Transmissíveis - ITS's e falamos, também, sobre o uso da camisinha feminina e masculina. Por nossa aula ser no refeitório, área comum a todas(os) da escola, as(os) alunas(os) de outras turmas sempre viam trechos das nossas discussões no momento em que saiam para beber água. Algumas/alguns estudantes muitas vezes até resistiam em voltar para suas salas de aula (Cena 3 - $5^{\circ}$ encontro - 06 de abril de 2016).

Nos últimos anos, apesar de os investimentos nos diálogos sobre as questões de gênero, sexualidade e etnia/raça no espaço escolar, muitas das vezes há empecilhos por parte de docentes e gestão escolar ou até de algumas famílias para que esses debates não sejam abordados, mesmo que estes invadam os espaços escolares sem pedir licença.

Durante o minicurso foi notório que, nos momentos das discussões sobre sexualidade, sempre atraíamos estudantes. Inúmeras vezes, as(os) 
alunas(os) de outras salas eram pegas(os) saindo de outras aulas para acompanhar as dinâmicas e/ou rodas de conversas ocorridas no minicurso. Éramos questionadas(os) todo o tempo sobre quando desenvolveríamos essas atividades em outras turmas.

Essas atitudes das(os) discentes nos apontam o quanto essas questões são sedutoras. Suzane Cabral e col. (2016) ao entrevistarem dezesseis estudantes de quatro turmas que cursavam a disciplina Educação para Sexualidade, componente curricular do núcleo diversificado dos anos finais do ensino fundamental das escolas municipais em Jequié-BA, identificaram que muitos(as) estudantes se sentem desconfortáveis e envergonhados(as) em dialogar com alguns/algumas de seus familiares mais velhos(as) e, dessa maneira, reconhecem a disciplina Educação para Sexualidade como um espaço importante para dialogarem sobre essas temáticas.

Apesar de boa parte das(os) estudantes desejar que essas temáticas se constituam como conhecimentos centrais nos currículos escolares, Britzman (2007) nos traz que existem muitos entraves para a construção de uma abordagem crítica da sexualidade na escola, dentre eles a persistência na estabilidade e fixidez das sexualidades e na preocupação excessiva com a transmissão de informações consideradas óbvias. Quiçá, as(os) docentes possam entender a sexualidade como instável, contestável e em movimento, se arriscando mais ao dialogar sobre sexualidade na escola, desaprendendo algumas ideias e pensamentos construídos e não temendo que as crianças e jovens se inquietem por saber sobre o sexo.

A quarta cena ocorreu quando estávamos discutindo sobre corpos objetificados e hipersexualizados e a visibilidade negra.

Como nem sempre a escola possuía salas de aulas vagas nos horários em que ocorria o minicurso, optamos por usar ambientes alternativos como o refeitório. Durante os encontros no refeitório muitos(as) funcionários(as) da escola como vigilantes e funcionárias da cantina e secretaria ficavam em volta. No decorrer da intervenção percebemos por muitas vezes burburinhos e comentários que não conseguíamos identificar. Porém, quando exibimos o vídeo chamado "O Globelezo", uma animação que mostrava como seria a reação das pessoas se ao invés de ter uma mulher negra com o corpo pintado sambando fosse um homem, a reação das(os) funcionárias(os) nos surpreendeu, pois elas(es) começaram a rir alto e balançaram as cabeças fazendo o sinal de negação (Cena 4 - $3^{\circ}$ encontro - 29 de março de 2016). 
As discussões sobre gênero, sexualidade e relações étnico-raciais não causa conflito apenas nas(os) estudantes, a comunidade escolar ainda traz consigo construções naturalizadas e estereotipadas sobre a temática, denunciada pelos seus trejeitos, olhares, expressões corporais que demonstravam o incômodo e a não concordância com os direcionamentos das discussões que elas(es) observavam.

Essas atitudes nos apontam que o caminho a ser trilhado nessas discussões ainda é longo. Às vezes ficamos focados nas(os) estudantes, e nos esquecemos de também dialogar com professoras(es), coordenadoras(es), funcionárias(os) de apoio, diretoras(es) e aí pode estar a armadilha, pois os discursos sexistas, racistas, etnocêntricos e lesbohomobitransfóbicos circulam também entre esses servidoras(es) das escolas e são (re)produzidos como verdades absolutas para as (os) estudantes.

A cena explicita o instante em que os(as) integrantes da escola extravasam o seu incômodo ao ver a animação "O Globelezo", externalizando em forma de altos risos e sinais de negação com as cabeças. Esta sátira foi produzida por Quadrinhos Ácidos e Bananinja e apresenta um homem negro musculoso sambando nu com o corpo pintado, enquanto um casal assiste ao vídeo em casa. Chama-nos atenção que enquanto a mulher diz que adorou ver o Globelezo, o homem se treme durante toda a exibição, algo que não ocorreria se ele estivesse assistindo a Globeleza, mostrando assim o incômodo que muitos homens têm ao ver outro dançando nu na televisão. Todavia também podemos questionar o porquê de ser um homem negro na animação, pois de alguma forma continua-se associando os homens negros à hipersexualização do corpo, o que não ocorre com os homens brancos.

Durante anos de nossas vidas convivemos e naturalizamos a objetificação da mulher negra com seu corpo seminu pintado fazendo um convite para o carnaval brasileiro em nossas telas de televisão, sem qualquer constrangimento ou tipo de problematização sobre a cena. Gonzalez (1984) nos traz que a mulher negra foi construída sob várias imagens, dentre elas, a de mulata, doméstica e mãe preta que foram naturalizadas, não as reconhecendo para além dessas construções. A autora narra como no Carnaval, especialmente, no Rio de Janeiro, a mulher negra se tornou a mulata que rebola bem, mexe a barriga, samba melhor e é assanhada. Há uma violência simbólica construída em torno da mulher negra e desse lugar de objetificação sexual pelos homens brancos, reiterado, mormente, no Carnaval. Fica a pergunta: por que, no ensino de Ciências, essas leituras raciais e étnicas so- 
bre os corpos são invisibilizadas? Quais os possíveis caminhos para essas rupturas com o ideário da branquitude?

\section{Vulnerabilidade Feminina: sexualidade restrita e violência doméstica}

No ensino de Ciências, quando nos dispomos a abordar sobre o uso da camisinha para a anticoncepção e o não contágio das infecções sexualmente transmissíveis, em geral nos apegamos a ensinar como o preservativo deve ser usado e a prescrevê-lo em todas as relações sexuais indiscriminadamente, inclusive falamos pouco do preservativo feminino, priorizando o masculino. Ademais, poucas vezes debatemos sobre como as relações de gênero afetam os relacionamentos e, consequentemente, o uso ou não da camisinha e, no caso, da contracepção, de outros métodos, intensificando, na maioria das vezes, a vulnerabilidade das mulheres.

A cena descrita e analisada a seguir ocorreu no encontro em que debatemos sobre Saúde sexual e os direitos das(os) adolescentes.

Estávamos em uma discussão sobre o uso da camisinha quando a aluna Jéssica se levantou e dirigiu-se até Danielle. Ela perguntou em particular: "Meu namorado me falou que quando perdemos a virgindade não precisamos usar camisinha, pois na primeira vez que transamos não engravidamos, nem pegamos nenhuma Doença Sexualmente Transmissivel - DST. Isso é verdade"? Danielle explicou que na relação sexual vaginal sem uso da camisinha pode-se engravidar e nas demais relações sexuais, caso não se use o preservativo, também se pode contrair alguma IST (Cena 5 - $5^{\circ}$ encontro - 06 de abril de 2016).

Em um dos seus escritos, Louro (2000) afirmou que a sexualidade feminina foi cerceada, algo que as mulheres falavam com alguém muito próximo e de forma escondida e recruza. Isso também fica perceptível quando em uma discussão em sala de aula uma aluna não se sente à vontade em tirar sua dúvida relacionada à sexualidade na frente das(os) seus colegas de turma. A sexualidade da mulher era vista restritamente ao particular e ao pessoal sem articulação com o contexto sociocultural. Essas sexualidades eram pensadas apenas em vivências heterossexuais, destinadas à reprodução, negando o prazer à mulher e, sendo permitida somente na fase adulta da vida. 
Nesta cena percebemos como o prazer do namorado está acima da segurança sexual da garota. Essas situações de vulnerabilidade, submissão e desconhecimento sobre o uso da camisinha, a concepção e os meios de contágio das IST's favorecem para que muitas mulheres engravidem sem desejar ou contraiam IST's no Brasil. Meyer, Klein e Andrade (2007, p. 223) já diziam que "[...] a sexualidade feminina é passiva, dirigida ao prazer dos homens [...]" e com isso as mulheres ficam subordinadas aos desejos dos seus parceiros, muitas vezes, confiando de forma irrestrita neles.

Em outra cena, ocorrida no último encontro, uma das estudantes relata que a sua tia foi assassinada pelo marido. Muitas vezes, em aulas de Ciências, pensamos que as discussões sobre sexo e gênero devem se restringir às descrições anatômico e fisiológicas dos corpos, desconsiderando as questões socioculturais que atuam nas construções identitárias de gênero e também produzem as múltiplas formas de violência, incluindo aquelas contras as mulheres cisgêneras, travestis e mulheres transgêneras que, em nosso país, apresenta índices elevadíssimos.

Durante o último encontro do minicurso, que tinha como tema Sexismo, Racismo, Homofobia, após apresentação de um vídeo do programa A Liga, que tratava sobre violência contra a mulher, nós, ministrantes, iniciamos as discussões sobre o vídeo e falamos sobre a necessidade de se denunciar os casos de agressão. Neste momento a aluna Maria pediu para relatar uma situação que vivenciou. Neste instante a sua amiga que estava ao seu lado, segurou suas mãos e falou: "Não precisa falar!" Mas, Maria insistiu em continuar e contou: "Essa questão de violência contra a mulher é algo que acontece sempre em minha família mesmo, pois minha tia foi morta pelo marido dela. Minha tia sempre apanhava do marido. Ele batia muito nela, até na frente dos filhos. Ela apanhava tanto que chegava a desmaiar. A família toda falava com ela para dar uma queixa dele na delegacia. Um dia minha tia resolveu dar uma queixa. Ela foi até a delegacia da mulher, chegou lá, fez a queixa contra o marido e voltou com a queixa na mão para a casa. Quando chegou a casa, ela avisou ao marido que tinha dado a queixa contra ele e eles começaram a brigar. E ele matou minha tia na frente dos filhos, meus primos, com facadas". Após o relato, a aluna estava chorando, e eu e Danielle também caímos em lágrimas. Ela continuou: "Agora professora, meus primos estão no abrigo, porque ninguém teve condições de ficar com eles" (Cena 6 - $6^{\circ}$ encontro - 07 de abril de 2016). 
Esse relato de Maria causou várias sensações na primeira autora deste texto que presenciou a narrativa da estudante. Por ser mulher negra e perceber a vulnerabilidade que também a atinge, foi tocada pela fala de Maria e se inquietou em perceber o quanto a violência contra as mulheres ainda tem sido difícil de ser combatida e, mesmo quando uma mulher denuncia essas agressões, ela continua exposta ao processo, quando não morta por ter denunciado, como foi o caso da tia de Maria. Entendemos que as políticas da segurança pública em nosso país ainda não conseguem garantir a vida das mulheres que não se calam diante desta violência e o espaço escolar que poderia se configurar como um local de resistência e da desconstrução dessa violência silencia-se diante dos índices alarmantes publicados anualmente.

Conforme o Atlas da Violência publicado em 2020, 4.519 mulheres foram assassinadas no Brasil em 2018, tendo como base o Sistema de Informação sobre Mortalidade do Ministério da Saúde (SIM/MS). Embora tenha havido uma queda de 9,3\% dos assassinatos quando comparado com 2017, no período de 2008 a 2018 o Brasil teve um aumento de 4,2\% nos assassinatos de mulheres. Entretanto, esse aumento ocorreu no assassinato de mulheres negras. A taxa de homicídios entre mulheres brancas diminuiu $11,7 \%$ entre 2008 a 2018 , enquanto a de mulheres negras aumentou $12,4 \%$. Das 4.519 mulheres mortas em 2018, 68\% eram negras. Na Bahia, das 427 mulheres assassinadas em 2018, 89,3\% delas eram negras.

Por termos desenvolvido nosso trabalho em uma escola quilombola, em que muitas das estudantes são mulheres negras, é relevante visibilizar esse debate a fim de que elas compreendam o quanto estão propensas à letalidade pela violência de gênero e que construam ações de resistência frente a esse grave problema de sociedades patriarcais, racistas, etnocêntricas e sexistas como a nossa (GOMES, 2018).

\section{Considerações finais}

Neste trabalho percebemos como discutir sexualidade, gênero e relações étnico-raciais no espaço escolar ainda incomoda e perturba muitos(as) de suas/seus integrantes, por isso, muitas vezes somos identificadas(os) como subversivas(os), o que nos lembrou o filme "O Sorriso de Monalisa", especificamente a cena da demissão da professora e enfermeira Amanda Armstrong. A motivação da sua demissão foi por ser vista como al- 
guém que incentivava a promiscuidade ao distribuir métodos contraceptivos as suas estudantes. Embora este filme seja passado nos anos 1950, muitas(os) docentes são ameaçadas(os) ainda hoje quando ousam abordar temáticas como essas.

Talvez, nas aulas de Ciências tenhamos brechas para trabalhar essas temáticas indo além das questões anatômico-fisiológicas, revisitando-as e analisando como as construções socioculturais afetam as nossas leituras sobre os corpos, os gêneros e as sexualidades. Arriscamo-nos a produzir aulas de Ciências em que nossos corpos marcados por diferentes subjetividades não se escondam frente aos processos discriminatórios como o sexismo, machismo, racismo e etnocentrismo que insistem não somente em padronizá-los, mas também corrigi-los.

\section{Referências}

BRASIL. Ministério da Economia. Atlas da violência 2020. Brasília: Instituto de Pesquisa Econômica Aplicada, 2020.

BRITZMAN, D. Curiosidade, sexualidade e currículo. In: LOURO, G. L. (org.). O corpo educado: pedagogias da sexualidade. 2 ed. Belo Horizonte: Autêntica, 2000, p. 83-111.

BOGDAN, R; BIKLEN, S. Investigação qualitativa em educação: uma introdução à teoria e aos métodos. Porto Editora: Portugal, 1994.

CABRAL, S. N.; SOUZA, M. L.; SOUZA, L. M.; SANTOS, B. R. L.; FIGUEIREDO, R. S.; CORTES, R. C. S.; SANTANA, F. X. S. 'É bom para conscientizar as pessoas das coisas que não são para fazer: o olhar das/os estudantes acerca do trabalho de temas relativos à sexualidade em um componente curricular na educação básica. Revista da SBEnBIO, v. 9, p. 7028 - 7038, 2016.

CARRIL, L. de F. B. Os desafios da educação quilombola no Brasil: o território como contexto e texto. Revista Brasileira de Educação, Rio de Janeiro, v. 22, n. 69, p. 539-564, jun. 2017. 
FERNANDES, V. B. O quilombo e a escola de Barro Preto, Jequié-Bahia: vicissitudes e sentidos de identidade. 2017. $251 \mathrm{f}$. Tese (Doutorado) - Faculdade de Educação, Universidade de São Paulo, São Paulo, 2017.

FURLANI, J. Educação sexual: possibilidades didáticas. In: LOURO, G. L.; FELIPE, J.; GOELLNER, S. V. (org.). Corpo, gênero e sexualidade: um debate contemporâneo na educação. Petrópolis: Vozes, 2003, p. 67-82.

GOMES, I. S. Feminicídios: um longo debate. Revista Estudos Feministas, Florianópolis, v. 26, n. 2, e39651, 2018.

GONZALES, L. Racismo e sexismo na cultura brasileira. Revista Ciências Sociais Hoje, Anpocs, p. 223-244, 1984.

LARROSA, J. Notas sobre a experiência e o saber da experiência. Revista Brasileira de Educação. Campinas, n. 19, p.20-28, 2002.

LOURO, G. L. Pedagogia da sexualidade. In: LOURO, G. L (organizadora). 0 corpo educado: pedagogias da sexualidade. 2 ed. Belo Horizonte: Autêntica, 2000.

LOURO, G. L.; MEYER, D. E. Dossiê Gênero e Educação. Estudos Feministas, ano 9, p. 513-514, 2001.

LOURO, G. L. Conhecer, pesquisar e escrever. Educação, Sociedade e Culturas, n. 25, p. 235-245, 2007.

MEYER, D. E. E.; KLEIN, C.; ANDRADE, S. dos S. Sexualidade, prazeres e vulnerabilidade: implicações educativas. Educação em Revista, n. 46. Belo Horizonte, p. 219-239, 2007.

MORO, C. C. A questão de gênero no ensino de Ciências. Chapecó: Argos, 2001.

ROSEMBERG. F. Educação Sexual na escola. Cad. Pesq. São Paulo. p. 11-19, 1985. 
SANTOS, L. H. S. dos. Incorporando "outras" representações culturais de corpo na sala de aula. In: OLIVEIRA, D. L. de. Ciências nas salas de aula. Porto Alegre: Mediação, 1997, p. 97-112.

SANTOS, F. F.; SOUZA, M. L. Educação, gênero e sexualidade: percursos e instabilidades do fazer-se pesquisadora/pesquisador-professora-professor. Revista Espaço do Currículo, v.8, p.209-222, 2015.

SILVA, E. P. de Q. As práticas e as produções curriculares das Ciências e Biologia sobre o corpo no ensino fundamental e médio. In: PEREIRA, M. G.; AMORIM, A. C. R. Ensino de Biologia: fios e desafios na construção de saberes. João Pessoa: Ed. Universitária/UFPB, 2008, p. 249-258.

SOUZA, M. L.; SANTOS, B. R. L. As discussões sobre gênero e diversidade sexual em livros didáticas de ciências do ensino fundamental II. Enseñanza de las Ciencias, v. extra, p. 1949-1953, 2013. 